\title{
THE
}

2018

\section{Developing Research Practitioners: Exploring Pedagogical Options for Teaching Research Methods in LIS}

\author{
Nicole D. Alemanne \\ Lauren H. Mandel \\ University of Rhode Island, lauren_mandel@uri.edu
}

Follow this and additional works at: https://digitalcommons.uri.edu/lsc_facpubs

The University of Rhode Island Faculty have made this article openly available.

Please let us know how Open Access to this research benefits you.

This is a pre-publication author manuscript of the final, published article.

Terms of Use

This article is made available under the terms and conditions applicable towards Open Access Policy Articles, as set forth in our Terms of Use.

\section{Citation/Publisher Attribution}

Alemanne, Nicole D. and Lauren H. Mandel. "Developing Research Practitioners: Exploring Pedagogical Options for Teaching Research Methods in LIS." Journal of Education for Library and Information Science, vol. 59, no. 3, 2018, pp. 26-40. http://dx.doi.org/10.3138/jelis.59.3.2018-0015.04

Available at: http://dx.doi.org/10.3138/jelis.59.3.2018-0015.04

This Article is brought to you for free and open access by the Graduate School of Library and Information Studies at DigitalCommons@URI. It has been accepted for inclusion in Graduate School of Library and Information Studies Faculty Publications by an authorized administrator of DigitalCommons@URI. For more information, please contact digitalcommons-group@uri.edu. 


\title{
Developing Research Practitioners: Exploring Pedagogical Options for Teaching Research Methods in LIS
}

\author{
Juried Paper ALISE' '18
}

\author{
Nicole D. Alemanne, PhD \\ Assistant Professor \\ Valdosta State University \\ Department of Library and Information Studies
}

Lauren H. Mandel, PhD

Assistant Professor

University of Rhode Island

Graduate School of Library and Information Studies

Preprint

\begin{abstract}
This paper reports on an investigation into the effectiveness of teaching research methods in library and information studies. A review of the literature revealed that the Library and Information Science (LIS) community is engaged in a continuing debate about the most effective means for teaching research methods courses in master's-level LIS programs. Many LIS master's students enter their programs lacking backgrounds in social science research and many students exhibit skepticism about the need for LIS practitioners to understand and engage in research. The small research project described in this paper was designed to contribute to this discussion by exploring how several different iterations of the final project implemented in a research methods course at the University of Rhode Island's (URI) LIS program contributed to student retention of learning outcomes after completing the course and the graduates' views of research and their engagement with research as practitioners. The authors developed a survey consisting of 20 closed-ended questions in single and matrix formats, covering three categories: respondents' experience with the course, their current use of research, and their opinion of research. The findings show promise for further research in the pedagogy of LIS research methods courses. Respondents demonstrated achievement and retention of course learning objectives and a generally positive attitude toward research.
\end{abstract}

Keywords: research methods, LIS education, LIS programs, LIS curriculum, LIS practitioners

\section{Introduction}

The Library and Information Science (LIS) community is engaged in a long-term debate about how best to teach research methods in LIS programs, especially considering the challenge inherent in the diversity of student academic backgrounds, as many enter LIS graduate programs with little or no research or statistics background and with anxiety about learning these subjects 
(Dilevko, 2000). And "many students who do take a basic course in research methods often cannot see the practical applicability of the course" (Berg, Hoffman, \& Dawson, 2009, p. 593). In light of this, LIS research methods courses must explain what research is, why research is done, the purpose of research, and how to use research, and must demonstrate the importance of research in professional settings (Juznic \& Urbanija, 2003; Mandel, 2017). This problem is not unique to LIS. Wagner, Garner, and Kawulich identified the lack of a "pedagogical culture" for teaching research methods in the social sciences (2011, p. 75).

This paper reports on a small study into the effectiveness of a research methods course taught in one LIS master's degree program, at University of Rhode Island's (URI) Graduate School of Library and Information Studies (GSLIS) in the United States (U.S.). The course is offered every fall and spring and some summers, and at the time of the study all students in the program were required to pass the course. Two faculty who have taught the course using the same textbook and similar learning objectives collaborated on a research project to evaluate the efficacy of different pedagogical methods for teaching research methods to LIS Mater's degree students. A survey comprising questions designed to test retention of course learning objectives and to ascertain respondents' views of research and their engagement with research as practitioners was distributed to former students from four semesters of the course. The results show promise for further research in the pedagogy of LIS research methods courses. Respondents demonstrated achievement and retention of course learning objectives, a positive attitude toward research in general, and moderate levels of engagement with research at work.

This study contributes to the discussion of the role of research methods courses in training LIS practitioners by implementing a research design that may be used for further research into the interplay among pedagogical methods, course outcomes, and professional research practice.

\section{Literature Review}

This review of the relevant literature covers three areas: the importance of research methods for LIS practitioners, an overview of approaches that have been employed to teach research methods, and the need for new approaches to teaching research methods.

In the U.S. a master's degree from a program accredited by the American Library Association (ALA) is the widely accepted professional degree for librarians (American Library Association, 2018a; Lynch \& Smith, 2001). Both the ALA Core Competences for Librarianship and the Standards for Accreditation of Master's Programs in Library and Information Studies include research. Research is ALA's Core Competence \#6: "fundamentals of quantitative and qualitative research methods" (6A), "central research findings and research literature of the field" (6B), and "principles and methods used to assess the actual and potential value of new research" (6C). The ALA accreditation standards stipulate that the curriculum in a master's program in LIS "emphasizes an evolving body of knowledge that reflects the findings of basic and applied research from relevant fields" (Standard II.2.1). The curriculum standards also include the need to educate librarians who can contribute to the "future development of a rapidly changing field" (Standard II.2.5), which could be taken to mean the ability to conduct research that promotes future development of LIS (American Library Association, 2018b, 2018c). 
Research is becoming more important for LIS practitioners as professionals: Ninety percent of U.S./Canadian LIS practitioners read at least one research journal, half apply research findings to their practice, and $42 \%$ occasionally or frequently perform research either in their job or for the profession (Juznic \& Urbanija, 2003). Also, it is important for LIS practitioners to contribute to the professional knowledgebase through research (Evans, Dresang, Campana, \& Feldman, 2013; Luo, 2011), and research is an essential component of LIS as a profession (Juznic \& Urbanija, 2003; McClure \& Bishop, 1989). Academic librarians may be required to conduct and report on research as part of their jobs (Berg, Hoffmann, \& Dawson, 2009). Research is less of a focus in other types of librarianship, but evaluation has become a substantial focus with the need for libraries to justify their worth through program evaluation and outcomes assessment (Kyrillidou, 2002; Stenström, 2015). Evaluation is one of the four purposes of research (Babbie, 2015), even if many librarians do not think of themselves as researchers when they are conducting evaluations.

About half of all ALA-accredited master's programs require research methods (Albertson, Spetka, \& Snow, 2015). How methods are taught varies widely. Practitioners indicate they see greater focus on reading and evaluating research than on conducting it (Powell, Baker, \& Mika, 2002). Even where methods are taught, data analysis remains a weakness of many research methods courses (Van Epps, 2012). Common assignments are research proposals, critique of research, and survey methodology (Luo, 2011; Park, 2004; Perkins \& Helbig, 2008; Smith \& Adams, 1992; Stephenson, 1990). Some have tried experiential learning (Evans et al., 2013; Mandel, 2017), an approach that has been proposed as a mechanism through which LIS students can learn to conduct research, analyze data, and present research findings (Berg et al., 2009; Evans et al., 2013; Liebscher, 1998; Luo, 2011). San Jose State University (SJSU) has taken a broader, more holistic approach to research methods in the LIS curriculum. The SJSU School of Information offers 10 research methods courses with different foci (e.g., Research in Youth Services, Evaluating Programs and Services, Ethnography) and students can choose one of the 10 to fulfill their research methods requirement. This allows students to opt into a course based on their perception of its relevance to their career or by interest level. Similarly, the University of Michigan offers eight courses that can be identified as related to research methods, evaluation, needs assessment, and data analysis (Luo, 2017).

No matter what LIS educators are endeavoring to teach with regard to research methods, the literature continues to emphasize the problem of proving the value of taking research courses to LIS students (Berg et al., 2009, p. 593). Considering this from the point of view of a student, if you don't see how a course is going to help you in your career, you are probably less likely to give that course $100 \%$ effort. Even with 10 courses being offered in an effort to give students a chance to focus on research more applicable to their career, SJSU still found that students felt the courses should offer more hands-on practice and focus on applied research (Luo, 2017). The call for new pedagogical approaches to teaching research methods in LIS master's degree programs has been ongoing for the past two decades (Dilevko, 2000; Juznic \& Urbanija, 2003; Koufogiannakis \& Crumley, 2006; Mandel, 2017).

In light of this, there is a need to develop new strategies to teach research methods in LIS programs (Juznic \& Urbanija, 2003), such as offering hands-on experience collecting and analyzing data (Evans et al., 2013) and providing opportunities for students to experience the full 
range of research activities from planning through publication in coursework (Mandel, 2017; Mandel, Estrella, Taft, \& Vaandering, 2016) and in field experiences (Berg et al., 2009). Research on the impact and efficacy of different pedagogical approaches in developing LIS practitioners who are comfortable with and expert in research is needed to inform LIS programs as they evaluate and revise research methods courses. While there are studies that explore specific pedagogical approaches to teaching research methods in LIS (e.g., Luo, 2017; Ondrusek, Thiele, \& Yang, 2014) and the effect of research methods courses on the work of LIS practitioners has also been investigated (e.g., Luo, 2011), this study adds to the conversation by developing a research design for exploring the interplay among pedagogical methods, retention of course learning objectives, and research practice in professional settings.

\section{Research Design}

The data presented here are based on the research methods course offered in the LIS program at URI, a publicly funded U.S. institution classified as Doctoral Universities: Higher Research Activity by the Carnegie Classification of Institutions of Higher Education (n.d.). GSLIS resides within the Harrington School of Communication and Media and offers the sole accredited LIS program in the New England region of the U.S. The course, LSC 557, was originally called Research and Evaluation in Library and Information Services and was renamed Document, Assess, Evaluate in 2014. Its catalog description is the "exploration of nature and role of library and information organizations and how information and organizational problems are identified and creative solutions are developed, implemented, and assessed in real-world settings." At URI faculty have wide latitude in selecting learning objectives, course topics, and assignments. As such, the research methods course has been taught in a variety of ways. During the time covered by this research, the course housed the Major Paper Requirement for non-thesis master's programs required by the university's Graduate School; this requirement was often met through the research proposal in the research methods course. Assignments across iterations of LSC 557 have included the research proposal (completed alone or in groups), a grant proposal, an individual research paper, article critiques, discussion boards, quizzes, in class practice exercises, and a research project conducted in collaboration with an outside client. LSC 557 was a required core course in the LIS program at the time of the research and was usually completed by students in the second half of the program. Learning outcomes of the course connect to understanding the importance, principles, and ethics of research and evaluation in library and information services; identifying the major contemporary research methods and theories, how they influence library and information services research, and how to critique and assess research in libraries and information services; making informed decisions by researching and evaluating libraries and information services, including users' needs, wants, and satisfaction levels; and understanding the steps related to developing and executing research.

The authors examined four semesters of the course: Fall 2013, Spring 2014, Fall 2015, and Spring 2016. These semesters were chosen for the research because the same textbook was used and similar content was taught across the four semesters, but multiple course delivery modes and approaches to the major project were employed (Table 1).

Table 1. Course Delivery Mode and Major Projects by Semester

Semesters Course Delivery Mode
Major Projects 


\begin{tabular}{lll}
\hline $\begin{array}{l}\text { Fall 2013 } \\
\text { Spring 2014 }\end{array}$ & Hybrid with 7 Face to Face meetings & $\begin{array}{l}\text { Individual grant proposal } \\
\text { Fall 2015 }\end{array}$ \\
Online asynchronous & $\begin{array}{l}\text { Team grant proposal \& individual } \\
\text { research paper }\end{array}$ \\
\hline Spring 2016 & $\begin{array}{l}\text { Online with 7 synchronous meetings } \\
\text { in WebEx }\end{array}$ & $\begin{array}{l}\text { Team research project for an outside } \\
\text { client }\end{array}$ \\
\hline
\end{tabular}

\section{Research Objectives and Research Questions}

The objectives of the study were to help improve the way LSC 557 is taught, benefitting future students and employers of those students, and to benefit the field of LIS as a whole by publishing results in the LIS literature to share lessons learned from the three iterations of the research methods course and best practices for teaching research methods in LIS. The research addressed three questions:

- RQ1: To what degree do the different approaches to the research proposal/research project assignment in LSC 557 affect students' achievement of course learning objectives?

- RQ2: To what degree do the different approaches to the research proposal/research project assignment in LSC 557 affect students' views of research after completing the course?

- RQ3: To what degree do the different approaches to the research proposal/research project assignment in LSC 557 affect students' engagement with research after completing the course?

\section{Survey Development}

The authors developed a survey consisting of 20 closed-ended questions in single and matrix formats, covering three categories: respondents' experience with the course, their current use of research, and their opinion of research. The development of the survey was collaborative; one author drafted a set of questions and the draft was revised in two rounds of edits. Google Forms (https://www.google.com/forms/about/) was used to create the survey because the University of Rhode Island uses G Suite for Education tools (https://edu.google.com) across the university. Table 2 delineates the number of survey questions that relate to each research question; the total number of survey questions noted in the table is less than 20 because the first two survey questions were used to identify the semester in which the respondents completed the course. Single answer multiple choice questions were used to address Research Question 1; Research Questions 2 and 3 were primarily addressed through matrix Likert questions.

Table 2. Number of Survey Questions per Research Question

Research Questions \# Survey Questions

1: To what degree do the different approaches to the research proposal/research project assignment in LSC 557 affect students' achievement of course learning objectives? 
2: To what degree do the different approaches to the research proposal/research project assignment in LSC 557 affect students' views of research after completing the course?

3: To what degree do the different approaches to the research proposal/research project assignment in LSC 557 affect students' engagement with research after completing the course?

The authors chose to employ a survey for data collection because the study was designed to quantitatively measure variations in learning outcomes by types of major project and a selfadministered survey was determined to be the most efficient way to collect the data. URI's IRB approved the project before the survey was administered.

\section{Data Collection and Analysis}

A database comprising 57 students who took LSC 557 in the four examined semesters (Fall 2013, Spring 2014, Fall 2015, and Spring 2016) was developed and emails inviting participation were sent to all 57 (a census rather than a sample was used because the results would be analyzed for course evaluation as well as pedagogical research). The survey was anonymous; the data were not linked to any specific participants in the study, and there was no danger of participants' responses affecting their employment.

Five of the email addresses were undeliverable and one represented the wrong student, leaving 51 good email addresses. Twenty surveys were completed, a 39\% response rate. The completed surveys split relatively equally among the three types of course delivery / major project combination: 35\% represented students in the Fall 2013 and Spring 2014 iterations $(n=7), 30 \%$ represented students from Fall $2015(\mathrm{n}=6)$, and 35\% represented students who completed the course in Spring $2016(n=7)$.

When the survey closed the authors realized that there was insufficient response to analyze the data at the level of course delivery / major project combination, meaning that the original goal of the project (to understand the effect of project type on respondents' retained knowledge of course learning objectives, their views of research after completing the course, and their current engagement with research) was not possible. However, the 20 completed surveys yielded a dataset for which descriptive statistics could be used to analyze the topline data. Therefore, the authors decided to use the data for exploratory purposes and to proceed with analyzing the responses for all respondents rather than breaking out the results by semester and project type.

\section{Findings}

Using descriptive statistics, the researchers were able to develop top-level findings for three topic areas: respondents' retained knowledge of course learning objectives, their views of research after completing the course, and their current engagement with research.

The first two survey questions were designed to identify the semester in which respondents completed the course and to test their memories of the type of major project completed in the course (individual research grant proposal, team research grant proposal, and team client 
project). Ninety percent of respondents matched the semester in which they completed the course with the correct major project. This result suggested that analysis of the 18 remaining survey questions would yield useable results.

\section{Retained Knowledge of Course Learning Objectives}

To gauge achievement of course learning objectives respondents were asked 12 multiple-choice questions querying their retained knowledge of course content. On all but three questions, 75\% or more of respondents answered correctly and $90 \%$ or more answered four questions correctly (Table 3).

Table 3. Percentage of Respondents Answering Content Questions Correctly

\begin{tabular}{ll}
\hline Question & \% \\
\hline If you were conducting a study using a sample of subjects who are available to & 95 \\
you, what type of sample would that be? & 90 \\
When a participant's identity is not known to the researcher we refer to this as & \\
what? & 90 \\
If you wanted to study the characteristics of a large population, which method & \\
would be most appropriate to use? & 90 \\
In an experiment, which group is the control group? & 85 \\
Which of the following is not a variable? & 85 \\
Qualitative data analysis is the method by which what kind of data is analyzed? & 80 \\
What type of research is conducted to determine the impact of a social & \\
intervention? & 80 \\
Which of the following are three elements of informed consent? & 75 \\
What type of research is conducted to identify why phenomena or events occur? & 70 \\
What is reliability? & 65 \\
Which level of measurement describes a variable that has attributes that are & \\
merely different? & \\
What is a research design? &
\end{tabular}

There wasn't a type of question that respondents found easier or harder or answer. The set of questions answered correctly by $90 \%$ or more of respondents covers sampling, human subjects protection, and methods. The set answered by $75 \%$ to $89 \%$ includes methods, human subjects protection, and research design.

\section{Views of Research and Comfort with Research Skills}

To understand their views of research after completing the course, respondents were asked for their views of the importance of research to the LIS field and for their jobs. In two questions asking about importance overall, $100 \%$ of respondents reported that research is important to the field and $60 \%$ reported that it is important for their jobs. Respondents were also asked about their 
views of specific types of research activities, coded on a 4-point scale: Strongly Agree (4), Agree (3), Disagree (2), Strongly Disagree (1), and Not Applicable (0). For the analysis of this question the 0 codes were dropped because those answers represented activities that respondents did not deem applicable to their jobs ( 0 answers represented $10 \%$ of the total 140 answers in this matrix question). For most statements the median response was "Agree" (3 on a 4 point scale) (Table 4).

Table 4. Agreement with Statements About Research (4-Point Scale)

\begin{tabular}{lcc}
\hline Statement & Median & Mode \\
\hline I like to read research articles & 3.0 & 3 \\
I understand the information in research articles & 3.0 & 3 \\
The information in research articles has an impact on my job & 3.0 & 3 \\
I understand how to conduct original research & 3.0 & 3 \\
I understand key issues of research ethics & 3.0 & 3 \\
The information I gather through original research has an impact on & 3.0 & 3 \\
my job & 2.5 & 3 \\
I like to conduct original research & & \\
\hline
\end{tabular}

Respondents reported having a relatively high comfort level with research skills after they finished the course. When answering a series of 15 questions, the median responses for all of the questions fell into the top two categories on a five-point scale, coded as Very Comfortable (5), Somewhat Comfortable (4), Not Very Comfortable (3), Not at All Comfortable (2), and N/A or I Don't Remember (1). In this analysis the bottom choice (N/A or I Don't Remember) was included because all the research skills included were covered in all iterations of the course covered in this research. Respondents reported being "somewhat comfortable" with nine areas of research skills and "very comfortable" with six areas. Respondents were most comfortable with skills related to general research knowledge, study preparation and planning, and two of the six methods queried. They were somewhat less comfortable with the majority of research methods and with tasks involved in analyzing data and communicating findings (Table 5).

Table 5. Comfort with Research Skills After Completing the Course (5-Point Scale)

\begin{tabular}{lll}
\hline Type of Skill & Very Comfortable (5/5) & Somewhat Comfortable (4/5) \\
\hline General knowledge & Purposes of research & \\
& Research ethics & \\
Preparation and planning & Reviewing literature & Defining variables \\
& Sampling & Operationalizing variables \\
Research methods & Survey & Content analysis \\
& Interview & Experiment \\
& & Focus groups \\
& & Observation \\
Data analysis & & Qualitative \\
& & Quantitative
\end{tabular}




\section{Current Engagement with Research}

The final area explored was respondents' engagement with research after completing the course. Respondents were offered 12 research activities that they might use at work and were allowed to choose as many as applied (so the total adds to more than 100\%). The top activities they reported using at work are accessing research articles to assist patrons $(55 \%)$, reading research articles for work-related projects (40\%), and accessing research articles for work-related projects (35\%). However, $40 \%$ of respondents reported not using research at work (Table 6).

Table 6. Current Use of Research at Work

\begin{tabular}{lc}
\hline Tasks & \% Use at Work \\
\hline Access research articles to assist patrons & 55 \\
Don't use research at work & 40 \\
Read research articles for work-related projects & 40 \\
Access research articles for work-related projects & 35 \\
Write literature reviews & 20 \\
Analyze data for research projects & 15 \\
Collect data for new research projects & 15 \\
Write research papers for publication & 5 \\
Write research reports & 5 \\
Develop research proposals & 0 \\
Other & 0 \\
Don't work & 0 \\
\hline
\end{tabular}

Respondents were also asked about their comfort level in completing research activities. When they were asked about their comfort level with research skills after completing the course, respondents reported feeling "very comfortable" or "somewhat comfortable" with all skills queried (Table 5). However, when asked specifically about their comfort level in completing research activities they reported somewhat lower levels of comfort. This question was coded on a 4-point scale: Very Comfortable (4), Somewhat Comfortable (3), Not Very Comfortable (2), Not at All Comfortable (1), and I do not do this (0). For this analysis the bottom response (I do not do this) was excluded from the analysis because the respondents were being queried about research activities that they use. All reported feeling "very comfortable" (median of 4.0 on a 4-point scale) with evaluating the quality of published research and they reported feeling "somewhat comfortable" (median 3.0) with the other tasks queried (Table 7).

Table 7. Comfort Level in Completing Research Activities (4-Point Scale)

\begin{tabular}{lcc}
\hline Activities & Median & Mode \\
\hline Evaluate the quality of published research & 4.0 & 4 \\
Write a literature review & 4.0 & 4 \\
Analyze qualitative data & 3.0 & 3 \\
Analyze quantitative data & 3.0 & 3 \\
Conduct a survey & 3.0 & 3 \\
Conduct content analysis & 3.0 & 3
\end{tabular}


Conduct interviews

Conduct observation research

Publish research findings

Conduct an experiment or quasi-experiment

\section{Discussion}

The results of this study show promise for further research in the pedagogy of LIS research methods courses. Survey respondents demonstrated retention of course learning objectives and a generally positive attitude toward research. The results were also very positive in the important area of developing intelligent consumers of research: Respondents reported being very comfortable with their understanding of the purposes of research, with research ethics, and with evaluating the quality of published research.

The respondents answered a majority of a series of questions designed to measure retention of course learning objectives correctly. Overall these are relatively good results but are not really informative in a deep way, especially as the initial intent of the study was to ascertain if the types of major project employed in different iterations of the course influenced the quality of retained course knowledge and engagement with research in practice. In addition there was no apparent pattern in the types of questions respondents answered more or less correctly. The authors did not conduct pretests of students' research knowledge at the beginning of each semester, but the persistence of knowledge past the end of the course demonstrated by this research does indicate some success in context of the literature review findings that many LIS graduate students have little or no research background and display anxiety about learning research concepts (Dilevko, 2000). Respondents also agreed with statements that they like to read research articles and understand the information in articles.

Another finding of the literature review is that LIS research methods courses must demonstrate to students the importance of research in professional settings (Juznic \& Urbanija, 2003; Mandel, 2017). The results of this research project show some success in this area as all respondents said that research is important to the field and $60 \%$ reported that it is important for their jobs. Research activities that respondents report using at work include accessing research articles to assist patrons, reading research articles for work-related projects, and accessing research articles for work-related projects.

Although respondents reported relatively high levels of comfort with research skills in general, they were somewhat less comfortable with the idea of completing a number of research tasks. For example, when asked about reviewing the literature and conducting surveys and interviews, respondents felt "very comfortable" in their skill levels after taking the course, but were "somewhat comfortable" in using those skills to conduct research. Respondents reported similar levels of comfort ("somewhat comfortable") with a number of research tasks, both when thinking about their general comfort level with the skills after taking the course and their comfort level in conducting activities as practitioners. This set of research activities includes most data collection methods, analyzing qualitative and quantitative data, and writing up research results. While participants reported that they understand how to conduct original research, how much these 
practitioners actually do understand about conducting research seems dependent on the method being used. When asked more specifically about comfort level in conducting research using different methods, respondents indicated more comfort with conducting surveys, content analysis, interviews, and observation than with conducting experiments or focus groups. Overall, it appears that respondents are more likely to use research knowledge to assist patrons and to learn from published research than to conduct original research.

\section{Limitations of the Research}

There are two major limitations of this research that are connected to each other. Although this study had a good response rate, the relatively small population of potential respondents drawn from four semesters of one course in one LIS program resulted in a dataset built from 20 survey responses. This relatively low $\mathrm{N}$ meant that the authors were unable to pursue the original intent of the project: to understand the effect of project type on respondents' retained knowledge of course learning objectives, their views of research after completing the course, and their current engagement with research. Another limitation is that even with a larger sample size the research would only be generalizable to the GSLIS program. Finally, this is essentially a pilot of the survey as it was developed for this project and was not pretested.

\section{Implications and Future Work}

Further research with larger samples is needed to understand the impact on course learning outcomes of different pedagogical methods, such as applying an experiential learning approach in which students complete research projects for clients versus developing research proposals. Another important area to address is the connection of results to the types of libraries in which respondents work and respondents' roles at work. Forty percent of respondents reported that they do not use research at work. It would be enlightening to explore this result in greater depth. How connected is it to the type of library and role, and how much is it influenced by a librarian's comfort level with doing research? Finally, it is important to conduct research that explores the interplay of specific course delivery methods (e.g., blended online versus asynchronous) and pedagogical approaches. This study presents a research design that can be augmented to address these questions. The next step in this research stream is to revise the survey based on learning from the current analysis and to extend the research to a second U.S. LIS program. This will allow the authors to augment the current dataset and to extend the findings beyond a single program.

\section{Conclusion}

The investigation into the effectiveness of teaching research methods to master's-level students in library and information studies programs reported on in this paper produced initial results that show promise for further research and the paper outlines an approach that can be used to answer further questions. Survey respondents demonstrated achievement and retention of course learning objectives, a positive attitude toward research in general, and moderate levels of engagement with research at work. However, the findings also demonstrate the limitations of conducting research on small samples from individual LIS programs, suggesting that expanding the research to include more LIS programs and research methods courses may prove fruitful. 
This research does show that practitioners who have completed a research methods course as part of their LIS Master's degree value research and use research in their work. They might be more comfortable reading and evaluating research conducted and reported by others than they are conducting research themselves. If the field wants practitioners to do research and not just be consumers of research, then there needs to be continued discussion of how research methods courses in LIS Master's degree programs can generate research practitioners, not just research consumers.

\section{Acknowledgements}

The authors wish to thank the former students who participated in this survey.

\section{References}

Albertson, D., Spetka, K., \& Snow, K. (Eds.). (2015). Library and information science education statistical report 2015. Seattle, WA: Association for Library and Information Science Education. Retrieved from https://ali.memberclicks.net/assets/documents/statistical_reports/2015/alise_201 5_statistical_report.pdf

American Library Association. (2018a). ALA accredited programs. Retrieved from http://www.ala.org/educationcareers/accreditedprograms/home

American Library Association. (2018b). Core competencies. Retrieved from http://www.ala.org/educationcareers/careers/corecomp/corecompetences

American Library Association. (2018c). Standards, process, policies, and procedures (AP3). Retrieved from http://www.ala.org/educationcareers/accreditedprograms/standards

Babbie, E. R. (2015). The practice of social research (14th ed.). Boston, MA: Cengage Learning.

Berg, S. A., Hoffman, K., \& Dawson, D. (2009). Integrating research into LIS field experiences in academic libraries. The Journal of Academic Librarianship, 35(6), 591-598. doi:10.1016/j.acalib.2009.08.007

Carnegie Classification of Institutions of Higher Education (n.d.). Institution lookup. Retrieved from http://carnegieclassifications.iu.edu/lookup/lookup.php

Dilevko, J. (2000). A new approach to teaching research methods courses in LIS programs. Journal of Education for Library and Information Science, 41(4), 307-329. doi:10.2307/40324048

Evans, A., Dresang, E., Campana, K., \& Feldman, E. (2013). Research in action: Taking classroom learning to the field. Journal of Education for Library and Information Science, 54(3), 244-252.

Juznik, P., \& Urbanija, J. (2003). Developing research skills in library and information science studies. Library Management, 24(6/7), 324-331. doi:10.1108/01435120310486048

Koufogiannakis, D., \& Crumley, E. (2006). Research in librarianship: Issues to consider. Library Hi Tech, 24(3), 324-340. doi:10.1108/07378830610692109

Kyrillidou, M. (2002). From input and output measures to quality and outcome measures, or, from the user in the life of the library to the library in the life of the user. The Journal of Academic Librarianship, 28(1), 42-46. doi:10.1016/s0099-1333(01)00299-3 
Liebscher, P. (1998). Quantity with quality? Teaching quantitative and qualitative methods in and LIS Master's program. Library Trends, 46(4), 668-680.

Luo, L. (2011). Fusing research into practice: The role of research methods education. Library and Information Science Research, 33(3), 191-201. doi:10.1016/j.lisr.2010.12.001

Luo, L. (2017). Diversified research methods education in LIS: Thinking outside the box. Journal of Education for Library and Information Science, 58(2), 49-63. doi:10.12783/issn.2328-2967/58/2/1

Lynch, B. P., \& Smith, K. R. (2001). The changing nature of work in academic libraries. College \& Research Libraries, 62(5), 407-420. doi:10.5860/crl.62.5.407

Mandel, L. H. (2017). Experiencing research firsthand: the "unClassroom" experiential learning approach to teaching research methods in an LIS Master's program. Journal of Education for Library and Information Science, 58(4), 187-201. doi:10.12783/issn.23282967/58/4/1

Mandel, L. H., Estrella, D., Taft, A., \& Vaandering, A. (2016, October). Grad students + libraries $=$ successful partnerships. Paper session presented at the New England Library Association Conference, Danvers, MA

McClure, C. R., \& Bishop, A. (1989). The status of research in library/information science: Guarded optimism. College \& Research Libraries, 50(2), 127-143. doi:10.5860/crl_50_02_127

Ondrusek, A. L., Thiele, H. E., \& Yang, C. (2014). Writing abstracts for MLIS research proposal using worked examples: An innovative approach to teaching the elements of research design. College and Research Libraries, 75(6), 822-841. doil0.5860/crl.75.6.822

Park, S. (2004). The study of research methods in LIS education: Issues in Korean and U.S. universities. Library and Information Science Research, 26(4), 501-510. doi:10.1016/j.lisr.2004.04.009

Perkins, G. H., \& Helbig, T. L. (2008). The value of LIS schools' research topics to library authors' professional work. The Journal of Academic Librarianship, 34(6), 513-519. doi:10.1016/j.acalib.2008.09.002

Powell, R. R., Baker, M. N., \& Mika, J. J. (2002). Library and information science practitioners and research. Library \& information science research, 24(1), 49-72. doi:10.1016/s07408188(01)00104-9

Smith, N. M., \& Adams, I. (1992). Characteristics of research courses in library schools. Journal of Education for Library and Information Science, 33(1), 75-78. doi:10.2307/40323488

Stenström, C. (2015). Demonstrating value: Assessment. In S. Hirsch (Ed.), Information services today: An introduction (pp. 271-277). Lanham, MD: Rowman \& Littlefield.

Stephenson, M. S. (1990). Teaching research methods in library and information studies programs. Journal of Education for Library and Information Science, 31(1), 49-65. doi:10.2307/40323727

Van Epps, A. S. (2012). Librarians and statistics: Thoughts on a tentative relationship. Practical Academic Librarianship: The International Journal of the SLA Academic Division, 2(1), i-xiii. doi:10.2307/40323727

Wagner, C., Garner, M., \& Kawulich, B. (2011). The state of the art of teaching research methods in the social sciences: towards a pedagogical culture. Studies in Higher Education, 36(1), 75-88. doi:10.1080/03075070903452594 